\title{
Biodegradable Polymeric Fiber Structures in Tissue Engineering
}

\author{
Kadriye Tuzlakoglu, Ph.D., and Rui L. Reis, Ph.D.
}

Tissue engineering offers a promising new approach to create biological alternatives to repair or restore function of damaged or diseased tissues. To obtain three-dimensional tissue constructs, stem or progenitor cells must be combined with a highly porous three-dimensional scaffold, but many of the structures purposed for tissue engineering cannot meet all the criteria required by an adequate scaffold because of lack of mechanical strength and interconnectivity, as well as poor surface characteristics. Fiber-based structures represent a wide range of morphological and geometric possibilities that can be tailored for each specific tissue-engineering application. The present article overviews the research data on tissue-engineering therapies based on the use of biodegradable fiber architectures as a scaffold.

\section{Introduction}

$\mathbf{F}$ IBERS ARE THE fundamental units of textile and fabrics. They can be directly supplied from nature or produced from synthetic polymers. Natural and synthetic fibers and fiber-based structures, so-called biotextiles, have been widely used for biomedical applications.

Biotextiles have been defined as a "structure composed of textile fibers and designed for used in a specific biological environment (e.g., surgical implant), where its performance depends on its interactions with cells and biological fluids as measured in terms of its biocompatibility and biostability." ${ }^{1}$

Polymeric fibers that are used in medicine can be manufactured using three main techniques: melt spinning, ${ }^{2}$ dry spinning, and wet spinning. ${ }^{3}$ All of these techniques are based on an extrusion of a polymer melt or solution. In melt spinning, a molten polymer with a suitable viscosity is extruded at high pressure and constant rate through a spinneret to form continuous strands of polymeric fibers. Cooling gases then solidify the formed fibers. Lubricants and finishing oils are sometimes applied to the fibers in a spin cell. In the next step, an initial drive roll, which controls the initial take-up speed, rolls the fibers. The fibers may undergo subsequent heating and stretching to give them molecular orientation. Finally, a special control device takes the fibers up onto bobbins at a constant speed. A melt spinning technique can be applied to almost all commercially available biodegradable polymers. The main disadvantage of this process for biodegradable polymers is that these polymers can degrade during the process because of the melting. In the dry spinning process, a similar approach is used to produce polymeric fibers. The main difference between these two processes is that, in dry spinning, the process starts from a polymer solution where it is a polymeric melt in melt spinning as described above. The most important thing to be considered here is finding a suitable and volatile organic solvent for the used polymer. After the extrusion of the polymer solution through tiny holes of a spinneret, the heated air or gas stream into the spinneret zone is used to remove the solvent from the filaments. Finally, the fibers are taken up onto the rolls as in melt spinning. Wet spinning is the oldest and most complicated method of fiber spinning. As in dry spinning, the polymer is dissolved in a suitable solvent, but there is no need for a volatile solvent in this process. The most important part of this process is the coagulation bath that the polymer enters after passing through a spinneret. The bath reacts chemically to coagulate the polymer, or it draws out the solvent from the polymer stream so that the filament can harden. In most cases, the second liquid is aqueous. A main difference between wet spinning and melt or dry spinning is that it is spinning into a fluid with a much higher viscosity. Because of this higher viscosity, higher shearing stress occurs on fiber surfaces, which introduces high tension into the filaments. This technique is mainly used for natural polymers, which can not dissolve in a volatile solvent and degrade before their melting points.

The final properties of the fibers produced using these three methods can be controlled using different finishing methods, for instance stretching ${ }^{4}$ or drying treatments, with different solvents. ${ }^{5}$ In addition to those main techniques, some

Biomaterials, Biodegradables and Biomimetics Research Group, Department of Polymer Engineering, University of Minho, Campus de Gualtar, Braga, Portugal.

Institute for Biotechnology and Bioengineering, PT Government Associated Laboratory, Braga, Portugal. 
special methods such as electrospinning ${ }^{6}$ and gel spinning ${ }^{7}$ are used in fiber processing. As we will discuss below, because of the structural similarity of electrospun polymeric mats to the natural extracellular matrix (ECM), the electrospinning process has attracted a great deal of attention in scaffold processing for tissue engineering. ${ }^{8}$ In a brief, this process is based on the generation of an electrical field between a polymeric solution (or a polymer melt) placed in a capillary tube with a small-diameter pipette or needle and a metal collector. When the electrical field reaches its critical value, repulsive electrostatic force overcomes the surface tension of the polymer solution, and a charged jet is produced. This charged polymeric jet then undergoes a stretching process that is accompanied by the rapid solvent evaporation and results in the formation of long, thin nanofibers. Electrospinning has been used to fabricate nanofibrous structures from a number of natural and synthetic polymers, such as collagen, ${ }^{9}$ chitosan, ${ }^{10}$ chitin, ${ }^{11}$ silk fibroin, ${ }^{12}$ hyaluronic acid (HA) ${ }^{13}$ poly(DL-lactide-coglycolide), ${ }^{14}$ poly(L-lactide) (PLLA) ${ }^{15}$ and polycaprolactone, ${ }^{16}$ among many others. Within the last few years, these nanofibrous structures have been used as scaffolds in many different tissue-engineering applications.

\section{Fiber Structures}

Fibers can be manufactured as monofilaments or multifilaments; they find, for instance, application as a suture in surgery. Sutures are the oldest and simplest example of textiles used in medicine. They are made of biodegradable and nondegradable polymers of natural or synthetic origin. Dexon ${ }^{\circledR}$ (polyglycolide; multifilament), Dexon Plus ${ }^{\circledR}$ (polyglycolide, braided), Vicryl ${ }^{\circledR}$ (poly[glycolide-L-lactide]; multifilament), Maxon $^{\circledR}$ (poly[glycolide-cotrimethylene carbonate]; monofilament), Biosyn $^{\circledR}$ (poly[glycolide-co-L-lactide-cotrimethylene carbonate]), and PDS ${ }^{\circledR}$ (poly p-dioxanone; monofilament) are the some examples of commercially available biodegradable sutures. ${ }^{17,18}$

For more-complex applications, fibers can also be formed in three-dimensional (3D) structures such as knitted, braided, woven, and nonwoven. The orientation of fibers in these structures may range from highly regular to completely random. The final structure of the fibers affects the behaviors of the fibers when they are applied. For example, woven structures have a more-stable and -porous structure than the other fiber structures. As a disadvantage, they can be unraveled at the edges when they are cut squarely or obliquely for implantation. Knit structures have an inherent ability to resist unraveling when cut and are flexible and porous, but sometimes their flexibility is reduced when additional yarns are used to interlock the loops to obtain more-stable structures. Additionally, difficulties in reducing their high porosity below a certain value is another clear disadvantage for some applications. Braided structures are mostly used as sutures. They can be designed using several different patterns, with or without a core. The spaces between the yarns, which cross each other, make them porous and help the fluid flow during the healing process. Non-woven structures may have a wide range of porosities. Their isotropic structure provides good mechanical and thermal stability. They can easily compress and expand. These advantages make them a suitable material for many tissue-engineering applications.

\section{Applications in Tissue Engineering}

Tissue engineering offers a promising new approach to create biological alternatives for regenerating different tissues. It typically involves the use of stem or progenitor cells seeded in a scaffold, which can guide the cell growth and tissue formation in three dimensions. Several requirements must be considered in the design of tissue engineering scaffolds, including high porosity, large surface area, adequate pore size, and uniformly distributed interconnected porous structures throughout the matrix. ${ }^{19-21}$

Biodegradable polymeric fiber structures can provide a large surface area and a large porosity (except electrospun ones), which can be optimized for specific applications. Besides these, many tissues, such as nerve, muscle, tendon, ligament, blood vessel, bone, and teeth, have tubular or fibrous bundle architectures and anisotropic properties. Therefore, fiber-based structures find a number of applications in tissue engineering, including soft tissue repair, vascular prostheses, bone and cartilage scaffolds, and nerve guides. Alternatively, many parameters must be considered in the design of fiber architectures, such as optimal fiber diameter and linear density, overall porosity and pore size distribution, influence of fiber orientation on cellular response, and influence of degradation on the properties of the structures.

\section{Soft tissue engineering}

Skin replacement. Skin is a complex organ and consists mainly of a superficial and an inner layer, called the epidermis and dermis, respectively. Most skin wounds can heal naturally, but replacement becomes a serious problem when burns, trauma, or disease irreversibly damages the skin. The most common approach for skin replacement is the use of autografts or allografts, ${ }^{22-24}$ but they have many limitations, including the creation of a donor site, risk of infection, and slow healing. Over the past 2 decades, tissue engineering approaches have been studied to construct a 3D skin architecture using a temporary scaffold combined with fibroblasts, keratinocytes, and endothelial cells. ${ }^{25,26}$ The majority of tissue-engineered structures used in skin replacement are freeze-dried biopolymer sponges combined with the abovementioned cells. However, freeze-drying is a labor-intensive, costly process that can produce sponges with significant structural heterogeneity. In addition, the pore structure and degree of porosity do not always perfectly allow the nutrient and oxygen transfer that are important factors in the skin replacement process. However, fiber-based scaffolds can overcome these problems by providing a high degree of porosity and structural integrity with high reproducibility, although other than the electrospun ones, they still can carry a risk of having bacterial infection because of their high porosity.

The use of biodegradable fiber-based structures has been proposed for healing of dermal or epidermal injuries. The most successful fiber-based dermal equivalents are the commercialized products Dermagraft ${ }^{\circledR}$ and Dermagraft-TC ${ }^{\circledR}$. Dermagraft is a structure consisting of fibroblasts, ECM, and a biodegradable fiber mesh. ${ }^{27} \mathrm{~A}$ polyglactin (PLGA) mesh is used as a scaffold for fibroblasts. The fibroblasts that proliferate into the scaffolds secrete human dermal collagen, matrix proteins, growth factors, and cytokines and create a dermal substitute. This has been applied clinically to patients 
with diabetic foot ulcers. It was found that healing was faster and better in patients with Dermagraft ${ }^{\circledR}$ treatment compared than in control patients (debridement and moist wound healing). ${ }^{28,29}$ Dermagraft-TC ${ }^{\circledR}$ is a Silastic covered form of Dermagraft ${ }^{\circledR}$ that acts as a nonbiodegradable form because of the covering. The Food and Drug Administration has approved its use as a dermal substitute. More recently, the PLGA knitted mesh has been combined with collagen microsponges for 3D culturing of skin fibroblasts. ${ }^{30}$ In this new hybrid approach, the PLGA knitted mesh serves as a scaffold to support the forming tissue while collagen microsponges help new and homogenous dermal tissue formation.

In addition to these commercialized synthetic fiber structures, natural fibers, such as chitin, chitosan, alginate, and a benzyl ester of HA (Hyaff 11), are also proposed for wound healing because of their wound healing ability. ${ }^{31}$ For instance, Hirano et al. $^{32}$ developed a new biocompatible dressing material made of wet-spun chitin-acid glycosaminoglycan fibers that released a portion of the glycosaminoglycan (GAG) into the body. Softness and easy handling of these fibers could be useful in the healing ot epidermal tissue injuries.

Many researchers have studied engineering of dermal tissue using a nonwoven scaffold based on a benzyl ester of HA. ${ }^{29,33-35}$ To obtain a nonwoven mesh structure, hyaluronan benzyl ester thread is produced using phase separation extrusion technology and then cut, carded, and needlepunched. For instance, Tonello et al. ${ }^{34}$ studied the coculturing of fibroblast and endothelial cells into a hyaluronan-based fiber mesh to create microcapillary-like structures in a dermal graft. Such a structure could aid in the healing of deeper lesions, where tissue vascularization is needed.

Electrospun nanofibrous mats have been also investigated as a novel wound dressing material. Nanofiber matrices show high oxygen permeability because of their high surface area $\left(5-100 \mathrm{~m}^{2} / \mathrm{g}\right)$, which also allows fluid accumulation at the wound site. ${ }^{36}$ Alternatively, their pore size is small enough to prevent bacterial penetration, making them a promising candidate for wound dressing. For instance, Katti et al. ${ }^{37}$ used an electrospinning method to produce antibioticloaded poly(lactide-coglycolide) nanofibrous membranes for wound healing. Collagen-based electrospun mats were also studied for using in tissue engineering applications, including wound healing. ${ }^{38}$

Vascular grafts. Biomedical textiles can find an application in the cardiovascular area, namely as vascular grafts. To mimic the soft, flexible structure of natural blood vessels, they have been used in woven, knitted, snf microporous tubular structures. Early attempts to develop a vascular graft focused on the use of bypass grafts made of nondegradable or degradable synthetic materials. The most-used nonbiodegradable synthetic polymeric fiber structures for this purpose are Dacron and Teflon. ${ }^{39-41}$ Later, fiber structures made of biodegradable polymers were applied as temporary scaffolds for the regeneration of blood vessels. The first proposed totally biodegradable vascular graft was PLGA 910 knitted mesh $\left(\right.$ Vicryl $^{\circledR}$ ) in 1979. Woven polyglycolic acid (PGA) structures have been also evaluated in a rabbit model as a vascular graft. $^{42}$

After many studies based on direct implantation of biodegradable grafts, tissue engineering approaches have started to be applied to the cardiovascular system in the development of a blood vessel substitute. For example, Kim et $a .^{43}$ studied the use of nonwoven PGA matrices, which were coated with PLLA to eliminate stability lack of PGA mesh, to design tissue-engineered constructs. The smooth muscle cells (SMCs) seeded onto these matrices had high cellular viability and produced a large amount of ECM proteins. Others have attempted to use surface hydrolyzed nonwoven PGA scaffolds for culturing SMCs. ${ }^{44}$ Nonwoven PGA scaffolds hydrolyzed using strong alkaline conditions have resulted in the creation of new functional groups (hydroxyl, carboxylic acid) and a decrease in fiber diameter. As a result of both changes in the scaffold, the SMCs seeded on them exhibit better adhesion capability and more-spread morphology than untreated PGA scaffolds. The morphological changes of the cell could be due to the surface functional groups that were not present before surface treatment, as could the increase in seeding efficiency. In another study, Shum-Tim et al. ${ }^{45}$ created a new vascular graft of nonwoven PGA mesh and biodegradable polyhydroxyalkanoate as an inner and outer layer, respectively. After 1 week of culture of a mixed cell population of endothelial cells, SMCs, and fibroblasts in these tubular structures, the final construct was implanted into a lamb. It has been observed that these tissueengineered constructs could resemble the native aorta and be used as vascular substitutes. In a later study, tubular scaffolds were designed from nonwoven PGA fabrics coated with a poly(L-lactide-cocaprolactone) (50/50) porous membrane. The constructs made of these scaffolds and mixed cells showed no occlusion or aneurysmal formation when they were implanted in dogs. Moreover, a line of endothelial cells was observed at the luminal surface of each autograft. More recently, these scaffolds have been successfully implanted with bone marrow cells into patients. ${ }^{46}$

To mimic the natural structure of blood vessels, $\mathrm{Xu}$ et al. ${ }^{47}$ have suggested the use of aligned nanofibrous poly(Llactide-co- $\varepsilon$-caprolactone) scaffolds produced using electrospinning and proposed that these systems be used for blood vessel engineering. They have reported that nanofibers can provide aligned attachment migration of SMCs along the axis of nanofibers In addition, it has been also found that distribution and organization of smooth muscle cytoskeleton proteins inside SMCs were parallel to the direction of the nanofibers.

Stankus et al. ${ }^{48}$ have proposed one of the most challenging approaches in blood vessel tissue engineering, which includes electrospinning and cell microintegration. They have used an electrospinning process to produce elastomeric tubular conduits form biodegradable poly(ester urethane) urea while vascular SMCs were microintegrated into these conduits using an electrospraying process that runs parallel to the electrospinning. As a result of this new production of blood vessel conduits, they obtained homogenous SMC integration into the electrospun tubular conduits.

Prosthetic heart valves. The other application of biodegradable polymeric fibers in the cardiovascular field is the tissue engineering of heart valves. The clinically available prosthetic heart valves include xenograft, mechanical, and homograft valves, but there are limitations to the long-term benefits of these valve prostheses, such as poor durability, foreign body reaction, infection, anticoagulation, and donor scarcity. Many studies have been undertaken to determine 
whether tissue-engineering principles could be used to develop valve tissue substitutes. Seeding of human fibroblasts, endothelial cells, or marrow stromal cells on biodegradable fiber mesh is a new approach for the creation of human autologous tissue-engineered heart valves. PGA nonwoven scaffolds are the most widely used materials for this purpose. ${ }^{49-51}$ To improve cell attachment and proliferation, PGA and PLA nonwoven fiber mesh structures have been coated with poly-4-hydroxybutyrate and their performance tested under dynamic conditions. ${ }^{52}$

Stents. Biodegradable fiber structures have also been proposed for use as stents. ${ }^{53-56} \mathrm{~A}$ stent is an expandable mesh tube that mechanically supports vessels against elastic recoil and reduces the restenosis rate in percutaneous coronary interventions. ${ }^{54}$ Biodegradable stents are used only when temporary airway stenting is needed. For instance, paclitaxel-loaded melt-extruded PLLA fibers have been tried as temporary stents. ${ }^{54}$ Furthermore, Saito et al. ${ }^{56}$ studied a biodegradable knitted stent made using PLLA in rabbit airways. The results have showed that the knitted tubular PLLA stents could be used like commercially available silicone stents. Nuutinen et al. ${ }^{53}$ developed a biodegradable stent from PLLA fibers using a braiding technique. These stents showed similar radial pressure stiffness as commercial metallic stents. They also studied the mechanical properties and in vitro degradation of biodegradable knitted stents made of polylactide, poly(L-lactide-co-D-lactide) and poly(L-lactidecoglycolide) fibers. ${ }^{55}$ It has been shown that the different chemical composition of these fiber structures provided for different degradation rates, which can be tailored for specific applications.

Nerve tissue regeneration. The nervous system is a complex, sophisticated system that regulates and coordinates body activities. It has two major divisions: the central nervous system and the peripheral nervous system. The central nervous system consists of the brain and the spinal cord, and the peripheral nervous involves all of the nerves that branch off from the spinal cord to the extremities. Neurons in the central nervous system have different characteristics and cannot regenerate by themselves. Therefore, restoration of their function is a major challenge in neurology. Recently, engineering of neural tissue using scaffolds with or without cells has become an alternative to traditional transplantation methods. For example, Yang et al. ${ }^{15}$ developed highly porous and fibrous PLLA scaffolds prepared using liquid-liquid phase separation methods to be used in nerve tissue engineering. These nanofibrous scaffolds showed an ability to support nerve stem cell differentiation and neurite outgrowth.

In the peripheral nervous system, injuries generally affect axons, which can be regenerated using a variety of methods, depending on how far the stumps are apart from each other. To avoid the problems of autografts and allografts, artificial nerve guidance channels have been developed. A nerve guide is a conduit that bridges the gap between the nerve stumps and directs and supports nerve regeneration. Most nerve guides reported in the literature have a rigid, solid structure from a number of natural or synthetic polymers such as collagen, ${ }^{57}$ alginate/chitosan, ${ }^{58}$ PLA and PLGA, ${ }^{59}$ and polyphosphoesters, ${ }^{60}$, They are mostly obtained by dipping a mandrel into a polymer solution several times until an ap- propriate thickness is achieved. They can then be used directly or freeze-dried to have porous structures. This method causes nonelastic final structure, although this can be overcome with freeze-drying or salt-leaching to achieve a porous structure. As a result of freeze-drying (or salt-leaching), the scaffolds created have a heterogeneous pore structure that does not provide proper guidance for the axons. Recently, nerve guides based on biodegradable fibers have been studied. For instance, Bini et al. ${ }^{61}$ fabricated a nerve guide from microbraided poly(L-lactide-coglycolide) fibers, which allowed for good nutrient transfer because of its microbraided structure. They observed successful regeneration in rats after 1 month of implantation. Later, they used the same approach to produce microbraided chitosan conduits. ${ }^{62}$ However, chitosan based conduits did not show the same success as poly(L-lactide-coglycolide) conduits because of the swelling characteristic of chitosan. A nerve guide made from poly (L-lactide-coglycolide) was also fabricated using an electrospinning method. ${ }^{63}$

A nerve guide made of collagen filaments has been proposed as an alternative to the tube-type nerve conduits. ${ }^{64}$ The collagen conduits consisting of 2,000 collagen filaments showed better regeneration than collagen tubes (as a control) in regeneration of rat sciatic nerve. In another study, synthetic biodegradable fibers made of PLLA were examined using dorsal root ganglia in vitro. ${ }^{65}$ PLLA filaments oriented the growth of Schwann cells and neurites along the longitudinal axis of the filament. In addition, better neurite growth has been observed when the filaments were coated with laminin. ${ }^{65}$ Steuer et al. ${ }^{66}$ also studied in vitro axonal outgrowth using polylactide filaments coated with rat Schwann cells. They demonstrated that axonal outgrowth on polylactide sheets coated with Schwann cells was 15 times better than on sheets without Schwann cells.

As another engineering approach, Cheng et al. ${ }^{67}$ reported successful axonal regeneration in rats as a result of implantation of a construct consisting of Schwann cells seeded on PLGA 910 fiber scaffolds and biomembrane.

\section{Hard tissue engineering}

Articular cartilage. Articular cartilage of the knee is a highly specialized connective tissue responsible for cushioning and lubricating. It is an avascular, aneural, alymphatic tissue that contains only one cell type, chondrocytes. Because of its avascular, low cellular nature, the self-healing capacity of articular cartilage is limited. Various techniques for repairing cartilage defects have been developed, including abrasion, ${ }^{68}$ drilling ${ }^{69}$ microfracture, ${ }^{70}$ osteochondral grafting, ${ }^{71}$ and transplantation of tissue-engineered constructs. ${ }^{72-74}$ Many different types of polymeric matrices with and without cells have been tested in vitro, as well as in experimental animals and in human patients, for their ability to promote articular cartilage repair. Recent trends are toward the use of fiber-based structures for engineering of articular cartilage. Most biodegradable fiber structures used are made using poly$\alpha$-hydroxy acid and HA. In embryonic tissue, hyaluronan is the main component of ECM and plays an important role in chondrogenic condensation during limb formation. ${ }^{75}$ It has been shown that HA can affect the differentiation of chondrocytes, $^{76}$ although it is difficult to form HA without any modification, and it can usually be modified using esterifi- 
cation. As was previously described, Hyaff is a derivative of $\mathrm{HA}$ and is being investigated as a scaffold for articular cartilage repair. For example, Brun et al. ${ }^{77}$ have compared Hyaff 7 and Hyaff 11 nonwoven meshes, which have the same fiber thickness $(20 \mu \mathrm{m})$ but different in vitro and in vivo degradation rates. Chicken embryo chondrocytes seeded in both structures maintained their phenotype and secreted ECM for up to 3 weeks of in vitro culture. Hyaff 11 nonwoven scaffolds with a slower degradation rate promoted a higher cell proliferation rate. They later reported on the use of Hyaff 11 nonwoven scaffolds as a support for mesenchymal progenitor cells that produced the main ECM molecules accompanied by an occasional synthesis of mature type II collagen. ${ }^{78}$ Moreover, when those structures were implanted in rabbit knees, with or without cells, there was no inflammatory response, and they degraded within 4 months after implantation. Other studies with human chondrocytes and mesenchymal stromal cells also confirmed that Hyaff 11 nonwoven meshes could promote the growth and differentiation of chondrocytes and production of collagen type II and aggrecan; they also down-regulate the production of collagen type I. ${ }^{79-81}$

Poly $\alpha$-hydroxy acid-based fibrous matrices have been widely investigated to serve as cartilage grafts. For instance, Freed et al. ${ }^{82-85}$ have performed several studies in which they used PGA fiber meshes and freshly isolated chondrocytes to investigate the influence of scaffold properties, as well as seeding and culture methods, on the development of cartilage constructions. Ma et al. ${ }^{86}$ have also investigated ways to engineer cartilage tissue by seeding articular chondrocytes onto PGA nonwoven scaffolds. They reported that, after the aggregate modulus of the engineered cartilage reached 179 $\pm 9 \mathrm{kPa}$ after 20 weeks of in vitro cultivation, which was $40 \%$ of that of natural articular cartilage.

To provide cells with the ability to suspend and make it possible to distribute cells within the polymeric mesh, synthetic nonwoven mesh structures have been combined with some naturally derived materials such as alginate, collagen, and fibrin. Using this approach, Ameer et al. ${ }^{87}$ have prepared a composite, composed of a polyglycolide nonwoven mesh coated with fibrin gel, for use in meniscal surgery. At 4 weeks of culture, GAG content in fibrin-coated PGA mesh scaffolds was found to be better than in uncoated PGA mesh scaffolds. In another similar study, PLGA meshes with two different compositions (slower-resorbing 47.5/52.5 PGA-PLA and faster resorbing 90/10 PGA-PLA) have been combined with chondrocyte-suspended alginate gel and tested in vitro and in vivo. Both types of coated copolymer pads showed uniform cell distribution and similar performance regarding expression of aggrecan, type I collagen, and type II collagen. ${ }^{88}$ However, the construct consisting of 47.5/52.5 PGA-PLA, alginate, and chondrocytes exhibited better performance when implanted in osteochondral defects of rabbits. It has also been shown that alginate stimulates the chondrogenic phenotype of the transplanted chondrocytes and prevents cells from floating out of the defects. Other researchers have used type I collagen for chondrocyte encapsulation and tried to combine this gel with nonwoven polylactide (PLLA) scaffolds. ${ }^{89}$ This method allowed a high number of chondrocytes to be homogeneously encapsulated into the scaffolds.

More recently, collagen type I has been also used to create web-like structures within the PLGA knitted meshes to achieve uniform cell distribution. ${ }^{90}$ The bovine chondrocytes seeded on these scaffolds have shown homogenous distribution, maintained their phenotype, and regenerated cartilaginous matrix, filling the void spaces in the scaffolds. To obtain thicker scaffolds, the cell-composite constructs have been laminated or rolled after 1 day of culture and implanted subcutaneously in the dorsum of athymic nude mice. In vivo results have demonstrated the formation of articular cartilage after 12 weeks of implantation. These new approaches have promised to generate structurally regular cartilage.

The use of bioreactors is a great challenge to obtain a homogenous scaffold-cell construct for cartilage and bone regeneration. Such systems can provide good nutrient transfer throughout the porosity of the scaffolds, which results in better cell migration and production of ECM in the interior part of the scaffolds. These systems have been successfully applied for creating a tissue-engineered cartilage construct using fiber-based scaffolds. Davisson et al. ${ }^{91}$ have reported the positive effect of perfusion on cell content and ECM production of bovine articular cartilage cultured PGA scaffolds. The synthesis of sulfated GAG has been found to be $40 \%$ higher than under static conditions. Griffon et al. ${ }^{92}$ compared two dynamic culturing techniques for culturing porcine chondrocytes on a scaffold composed of PGA mesh or chitosan sponge. A better, more-uniform cell attachment has been found when PGA scaffolds were used in the vacuumreactor system.

Finally, within the last few years, biodegradable nonwoven nanofibers, which are produced using electrospinning, have started to be used as scaffolds for regeneration of cartilage. A 3D matrix made of polycaprolactone nanofibers with a diameter of $700 \mathrm{~nm}$ have been proposed as a scaffold for cartilage tissue engineering. ${ }^{93}$ The primary chondrocytes that were seeded onto these scaffolds proliferated and efficiently maintained their differentiated phenotype, as indicated by the expression of cartilage-associated genes. In a later study, ${ }^{94}$ the same authors demonstrated that PCL nanofibrous scaffolds enhanced the chondrogenic differentiation of human mesenchymal stem cells (MSCs) significantly more than the cell pellet culture system, which is a widely used culture protocol for studying chondrogenesis of MSCs. Collagen-based nanofibrous scaffolds have also been proposed for cartilage tissue engineering. Collagen is a naturally occurring polymer and one of the major components of ECM of animal tissues. It is found in ECM in a fibrillar form with a diameter of 50 to $300 \mathrm{~nm}$. It has been shown that collagen type II can be electrospun as a nonwoven mat with a fiber diameter between $110 \mathrm{~nm}$ and $1.8 \mu \mathrm{m}$ and used as a scaffold for chondrocyte seeding. ${ }^{95}$

Bone. Bone is a complex, dynamic, highly vascular tissue with a large amount of ECM and limited cell population. As in all tissue engineering fields, many studies ${ }^{96-100}$ have been conducted to recreate the complexity, stability, and biologic function of bone tissue. The most common strategy for engineering of bone is to use a scaffold combined with osteoblasts or the cells that can mature or differentiate into osteoblasts and regulating factors that promote cell attachment, differentiation, and mineralized bone formation. ${ }^{101}$ The requirements for the design and production of an ideal scaffold for bone regeneration are complex and not yet fully understood. It is generally agreed that it must be a 
biocompatible, porous ( $>90 \%$ and pore sizes between 100 and $350 \mu \mathrm{m})$, interconnected, and permeable structure to permit the ingress of cells and nutrients. ${ }^{102}$ Structures designed with biodegradable fibers can meet all these criteria and serve as a scaffold for the engineering of bone. Many different fiber-based polymeric matrices have been tested with different cell types to create a bone construct. For instance, bone marrow cells seeded in a nonwoven HA polymeric scaffold (Hyaff 11) in a mineralizing medium and basic fibroblast growth factor have shown mineralization through the expression of the markers Calcium (Ca), alkaline phosphatase, osteopontin, bone sialoprotein, and collagen $\mathrm{I}^{103,104}$ Recently, Mikos et al. ${ }^{96,105}$ reported a study in which they used biodegradable fiber mesh scaffolds to create bone substitutes under dynamic culture conditions. In this study, rat bone marrow cells were seeded onto nonwoven PLLA scaffolds with a thickness of $1.7 \mathrm{~mm}$, a volumetric porosity of $99 \%$, and a fiber diameter of $17 \mu \mathrm{m} .^{96}$ These constructs were cultured in a flow perfusion bioreactor or under static conditions. It was found that nonwoven PLLA scaffolds could support the attachment, growth, and differentiation of rat bone marrow cells. Moreover, it has been reported that flow perfusion could accelerate calcified matrix deposition and provide a homogenous cell distribution though the interior part of the scaffold. Gomes et al. ${ }^{105}$ used the same approach to culture rat bone marrow cells in starch-based fiber mesh scaffolds. They observed greater osteogenic differentiation of bone marrow stromal cells when they cultured on starch-based fiber mesh scaffolds under dynamic conditions. They also reported that fiber-based structures were more advantageous than extruded porous structures because of their highly interconnected structure, which provides homogenous tissue formation.

We also developed chitosan-based nonwoven structures as bone tissue-engineered scaffolds using a traditional wet spinning technique. ${ }^{106}$ We demonstrated that chitosan nonwoven scaffolds had an ability to support osteoblast cell attachment.

As a new trend in the tissue-engineering field, nanofibrous scaffolds produced using an electrospinning process have been also suggested for bone tissue engineering. For example, nonwoven polycaprolactone nanofibrous scaffolds have been tested with MSCs derived from the bone marrow of neonatal rats under dynamic culture conditions. ${ }^{16}$ After 4 weeks of culture, at least the surfaces of the cell-polymer constructs were covered with cell multilayers. Additionally, these structures could support mineralization and production of type I collagen under dynamic culture conditions. However, colonization by cells of 3D electrospun scaffolds is a major problem because of the pore size of the scaffolds, which is typically less than average cell size. It has been shown that ${ }^{107}$ the mean pore radius of electrospun matrices varies with fiber diameter. For example, a 100-nm fiber diameter yields a mean pore radius of less than $10 \mathrm{~nm}$ at a relative density of $80 \%$. The comparative size of a rounded cell (ranging from 5 to $20 \mu \mathrm{m}$ ) shows that such small pore sizes will obstruct cellular migration. For a scaffold that requires minimal cellular infiltration (e.g., a vascular graft), proliferation limited to the surface may be acceptable or even desirable, but in the case of bone and cartilage, cell migration throughout the interior part of the scaffold is necessary to obtain $3 \mathrm{D}$ constructs that will create a targeted tissue later on. Additionally, it was also reported in the same study that electrospun scaffolds are not truly 3D structures because the fiber axes may be inclined only a few degrees with respect to the plane of the network. These 2D networks can be stacked upon one another and give a thicker scaffold, but the density of unit area increases with an increasing number of layers, which will reduce the mean pore size in this approach.

Related to electrospun mats, Li et al. ${ }^{108}$ have presented the next step in such nanofibrous PCL scaffolds by culturing human MSCs that can differentiate into adipogenic, chondrogenic, and osteogenic lineages in the same matrix. This promising result underscores the potential of using stem cells and nanofibers in bone tissue engineering. More recently, Jin et al. ${ }^{109}$ used the electrospinning technique to produce nanofibrous fiber mats with an average fiber diameter of $700 \pm 50 \mathrm{~nm}$ from silk fibroin with polyethylene oxide. In vitro culture studies with human bone marrow stromal cells have shown that these matrices, especially after polyethylene oxide extraction, could support initial cell attachment and ingrowth.

Tuzlakoglu et al. ${ }^{110}$ suggested a new approach to designing a structure that combines polymeric micro- and nanofibers in the same construct. This novel structure aims to serve as a scaffold and mimic the physical structure of ECM for bone tissue regeneration while simultaneously providing the macro support that cells require. Nano- and microfibercombined scaffolds have been produced from starch-based biomaterials using a fiber-bonding electrospinning two-step methodology. The cell culture studies with human osteoblastlike cell line (SaOs-2) and rat bone marrow stromal cells demonstrated that the presence of nanofibers influenced cell shape and cytoskeletal organization of the cells on the nanoand micro-combined scaffolds as well as cell viability and alkaline phosphatase activity.

In addition to the use of polymeric fiber structures as a scaffold, an application for a special kind of bone regeneration in dentistry has also been found, as a membrane for guided tissue regeneration (GTR). These barrier membranes prevent epithelial migration and promote the regeneration of new connective tissue attachment. Vicryl periodontal mesh and Gore Resolut (composed of polyglycolide fiber and trimethylene carbonate) have successfully been used for this application. ${ }^{111,112}$ A PLA-coated knitted PGA mesh was developed and suggested for use as a barrier membrane in GTR. ${ }^{113}$ Fujihara et al. ${ }^{114}$ have developed another GTR membrane composed of polycaprolactone and calcium carbonate using an electrospinning process.

Anterior cruciate ligament. Ligaments are bands or sheets of fibrous connective tissue between two or more bones and are responsible for providing motion and stability to joints and transmitting tensile loads in the musculoskeletal system. Ligaments consist mainly of collagen fibers that are formed into large bundles with a specific orientation. The anterior cruciate ligament (ACL) connects the femur to the tibia and acts as a primary stabilizer of the knee. A rupture of the ACL cannot heal, and a surgical reconstruction is required to restore normal joint function. Tissue engineering offers a potential technique to design ligament replacement grafts using a biodegradable scaffold with or without cells. An ideal scaffold for the ACL must provide a high degree of mechanical strength initially and lose its strength by gradually degrading 
while new tissue is remodelling. Because of the natural structure of the ACL, collagen-based fiber scaffolds are widely used for ACL replacement. ${ }^{115,116}$ The mechanical strength and the control of the rate of degradation of collagen scaffolds could be improved by crossolinking for instance with ultraviolet or carbodiimide. ${ }^{116}$ However, it has been shown that both cross-linking methods have different advantages with regards to final mechanical strength and the corresponding cell attachment. Silk is another natural polymer that has been proposed for tissue engineering of ACLs. ${ }^{117}$ When they are properly prepared, silk fiber matrices, which have good mechanical properties as well as biocompatibility and slow degradation, can serve as suitable matrices to support adult stem cell differentiation toward ligament lineages. HA-based fibers are another natural-origin alternative for ACL replacement. Cristino et al. ${ }^{118}$ have designed a prototype scaffold with a multilayered knitted cylindrical array of Hyaff 11 fibers oriented in two directions. They indicated that MSCs grown on these scaffolds could express collagen type I, collagen type III, laminin, fibronectin, and actin, which are the characteristic markers of the ligament tissue.

Alternative biodegradable materials in ACL reconstruction are the synthetic polymers (polydioxanone, polylactide, polyglycolide, and their copolymers). These materials have been proposed as implants for using directly or as scaffolds for creating 3D tissue-engineered constructs. Based on the first approach, commercially available polydioxanone has been suggested for ACL replacement, ${ }^{119}$ but it degrades quickly, which can be a problem for this application. It has been reported that polydioxanone loses half of its tensile strength in approximately 4 to 6 weeks, whereas the process for replacement can take up to 12 months. ${ }^{120}$ A similar problem has occurred when braided polyglycolide (Dexon) ligaments were used for replacement. For example, Cabaud et al. ${ }^{121}$ used braided polyglycolide (Dexon) ligaments, which showed $828 \mathrm{~N}$ maximum linear load at $22.6 \%$ strain, for the repair of ACL of dogs. Although they showed high initial strength, their degradation time was not long enough to protect the repaired ligament. In a later study, Laitinen et al. ${ }^{122}$ tested the mechanical properties of braided PLLA implants in vitro and after subcutaneous implantation in rabbits. These implants have shown better mechanical strength and a slower degradation rate than polydioxanone and PGA, which would be advantageous for reconstruction of the ACL. Within the last few years, biodegradable synthetic fibers have been formed into 3D scaffolds for the engineering of ACLs. Cooper et al. have developed a new braiding procedure to create $3 \mathrm{D}$ scaffolds with the desired pore diameter, porosity, mechanical properties, and geometry from different polyesters, namely PLLA, PGA, and polylactic-co-glycolic acid 82:18 (PLAGA). ${ }^{123,124}$ Although PGA scaffolds have shown the highest tensile strength, they have supported a lower level of ACL cell attachment and growth than PLAGA and PLA because of their fast degradation time and released degradation product during cell culture. Alternatively, fibronectin-coated PLLA scaffolds have provided for a better cell viability than PGA and PLAGA and maintained their structural integrity and high mechanical properties over the culture period. ${ }^{123}$ These results confirm that tissue engineering of ACLs using fiber-based scaffolds and ACL cells is a promising approach for ACL reconstruction.

CONCLUS ${ }^{3}$ Tissue engineering is a new approach that proposes the regeneration of tissues using stem or progenitor cells and scaffolds or artificial ECMs. The design of an ideal scaffold remains a problem in most tissue-engineering fields. Although it is specific for each tissue, it is generally agreed that biocompatibility, biodegradability, porosity, interconnectivity, and surface properties are the main requirements for an ideal scaffold. The fiber-based architectures described in this review seem to be promising scaffolds for many different tissue-engineering applications because of their highly porous and interconnected pore structures and their mechanical strength and structural integrity combined with a large surface area, but there are still many issues to be addressed, including the choice of a proper material, the combination and diameter of fibers (distinct for different applications and cell sources), and scaffold geometry for each specific application.

\section{Acknowledgments}

K. Tuzlakoglu thanks the Portuguese Foundation for Science and Technology for providing her a PhD scholarship (SFRH/BD/8502/2002). This work was partially supported by FCT Foundation for Science and Technology through funds from the POCTI and FEDER programs and by the European Union-funded STREP Project HIPPOCRATES (NMP3-CT-2003-505758). This work was carried out under the scope of the European NoE EXPERTISSUES (NMP3-CT2004-500283).

\section{References}

1. King, M.W. Designing fabrics for blood vessel replacement. Can. Textile J. 108, 24, 1991.

2. Fambri, L., Bragagna, S., and Migliaresi, C. Biodegradable fibers of poly-L,DL-lactide $70 / 30$ produced by melt spinning. Macromol. Symp. 234, 20, 2006.

3. Ellis, M.J. and Chaudhuri, J.B. Poly(lactic-co-glycolic acid) hollow fibre membranes for use as a tissue engineering scaffold. Biotechnol. Bioeng. 96, 177, 2007.

4. Solarski, S., Ferreira, M., and Devaux, E. Thermal and mechanical characteristics of polylactide filaments drawn at different temperatures. J. Textile Inst. 98, 2007.

5. Knaul, J., Hooper, M., Chanyi, C., and Creber, K.A.M. Improvements in the drying process for wet-spun chitosan fibers. J. Appl. Polymer Sci. 69, 1435, 1998.

6. Sell, S., Barnes, C., Smith, M., McClure, M., Madurantakam, P., Grant, J., McManus, M., and Bowlin, G. Extracellular matrix regenerated: tissue engineering via electrospun biomimetic nanofibers. Polymer Int. 56, 1349, 2007.

7. Kim, S.-H., Kwon, J.H., Chung, M.S., Chung, E., Jung, Y., Kim, S.H., and Kim, Y.H. Fabrication of a new tubular fibrous PLCL scaffold for vascular tissue engineering. J. Biomater. Sci. Polym. Ed. 17, 1359, 2006.

8. Ashammakhi, N., Ndreu, A., Piras, A.M., Nikkola, L., Sindelar, T., Ylikauppila, H., Harlin, A., Gomes, M.E., Neves, N.M., Chiellini, E., Chiellini, F., Hasirci, V., Redl, H., and Reis, R.L. Biodegradable nanomats produced by electrospinning: expanding multifunctionality and potential for tissue engineering. J. Nanosci. Nanotech. 7, 862, 2007.

9. Matthews, J.A., Wnek, G.E., Simpson, D.G., and Bowlin, G.L. Elelctrospining of collagen nanofibers. Biomacromolecules 3, 232, 2002.

10. Ohkawa, K., Cha, D., Kim, H., Nishida, A., Yamamoto, H. Electrospining of chitosan. Macromol. Rapid Commun. 25, 1600, 2004. 
11. Min, B.M., Lee, S.W., Lim, J.N., You, Y., Lee, T.S., Kang, P.H., and Park, W.H. Chitin and chitosan nanofibers: electrospining of chitin and deacetylation of chitin nanofibers. Polymer 45, 7137, 2004.

12. Jin, H.J., Fridrikh, S.V., Rutledge, G.C., and Kaplan, D. Electrospinning of bombyx mori silk with poly(ethylene oxide). Biomacromolecules 3, 1233, 2002.

13. Um, I.C., Fang, D., Hsiao, B.S., Okamoto, A., and Chu, B. Electro-spinning and electro-blowing of hyaluronic acid. Biomacromol. 5, 1428, 2004.

14. Li, W., Laurencin, C.T., Caterson, E.J., Tuan, R.S., and Ko, F.K. Electrospun nanofibrous structure:a novel scaffold for tissue engineering. J. Biomed. Mater. Res. 60, 613, 2002.

15. Yang, F., Murugan, R., Ramakrishna, S., Wang, X., Ma, Y.X., and Wang, S. Fabrication of nano-structured porous PLLA scaffold intended for nerve tissue engineering. Biomaterials 25, 1891, 2004.

16. Yoshimoto, H., Shin, Y.M., Terai, H., and Vacanti, J.P. A biodegradable nanofiber scaffold by electrospining and its potential for bone tissue engineering. Biomaterials 24, 2077, 2003.

17. Bourne, R.B., Andreae, P.R., Finlay, J.B., and Marquis, F. Invivo comparison for four absorbable sutures: Vicryl, Dexon Plus, Maxon and PDS. Can. J. Surg. 31, 43, 1988.

18. Hong, J.-T., Cho, N.-S., Yoon, H.-S., Kim, T.-H., Koh, M.-S., and Kim, W.-G. Biodegradable studies of poly(trimethylenecarbonate- $\varepsilon$-caprolactone)-block-poly (p-dioxanone), poly(dioxanone), and poly(glycolide- $\varepsilon$ caprolactone) (monocryl ${ }^{\circledR}$ ) monofilaments. J. Appl. Polymer Sci. 102, 737, 2006.

19. Mikos, A.G. and Temenoff, J.S. Formation of highly porous biodegradable scaffolds for tissue engineering. Electron. J. Biotechol. 3, 114, 2000.

20. Gomes, M.E., Malafaya, P.B., and Reis, R.L. Fiber bonding and particle aggregation as promising methodologies for the fabrication of biodegradable scaffolds for hard-tissue engineering, in biodegradable systems for tissue. In Reis R.L. and San Román J., eds. Engineering and Regenerative Medicine. Boca Raton, FL: CRC Press, 2004, p. 53.

21. Ikada, Y. Challenges in tissue engineering. J. R. Soc. Interface 3, 589, 2006.

22. Gibbs, S., Van Den Hoogenband, H.M., Kirtschig, G., Richters, C.D., Spiekstra, S.W., Breetveld, M., Scheper, R.J., and De Boer, E.M. Autologous full-thickness skin substitute for healing chronic wounds. Br. J. Dermatol. 155, 267, 2006.

23. Cuono, C., Langdon, R., and McGuire, J. Use of cultured epidermal autografts and dermal allografts as skin replacement after burn injury. Lancet 1, 1123, 1986.

24. Leigh, I.M., Purkis, P.E., Navsaria, H.A., and Phillips, T.J. Treatment of chronic venous ulcers with sheets of cultured allogenic keratinocytes. Br. J. Dermatol. 117, 591, 1987.

25. Schulz, J.T., Tompkins, R.G., and Burke, J.F. Artificial skin. Annu. Rev. Med. 51, 231, 2000.

26. Bello, Y.M., Falabella, A.F., and Eaglstein, W.H. Tissueengineered skin: current status in wound healing. Am. J. Clin. Dermatol. 2, 305, 2001.

27. Kirsner, S.K., Falanga, V., and Eaglstein, W.H. The development of bioengineered skin. Trends Biotech. 16, 246, 1998.

28. Edmons, M.E., Foster, A.V., and McColgan, M. "Dermagraft": a new treatment for diabetic foot ulcers. Diabet. Med. 14, 1010, 1997.

29. Zacchi, V., Soranzo, C., Cortivo, R., Radice, M., Brun, P., and Abatangelo, G. In vitro tissue engineering of human skin-like tissue. J. Biomed. Mater. Res. 40, 187, 1998.
30. Chen, G., Sato, T., Ohgushi, H., Ushida, T., Tateishi, T., and Tanaka, J. Culturing of skin fibroblasts in a thin PLGAcollagen hybrid mesh. Biomaterials 26, 2559, 2005.

31. Miraftab, M., Qiao, Q., Kennedy, J.F., Anand, S.C., and Groocock, M.R. Fibers for wound dressing based om mixed carbohydrate polymer fibres. Carbohydrate Polym. 53, 225, 2003.

32. Hirano, S., Zhang, M., and Nakagawa, M. Release of glycosaminoglycans in physiological saline and water by wetspun chitin acid glycosaminoglycan fibers. J. Biomed. Mater. Res. 56, 556, 2001.

33. Gallasi, G., Brun, P., Radice, M., Cortivo, R., Zanon, G.F., Genovese, P., and Abatangelo, G. In vitro reconstructed dermis implanted in human wounds: degradation studies of the HA-based supporting scaffold. Biomaterials 21, 2183, 2000.

34. Tonello, C., Zavan, B., Cortivo, R., Brun, P., Panfilo, G., and Abatangelo, G. In vitro reconstruction of human dermal equivalent enriched with endothelial cells. Biomaterials 24, 1205, 2003.

35. Caravaggi, C., De Giglio, R., Pritelli, C., Sommaria, M., Dalla Noce, S., Faglia, E., Mantero, M., Clerici, G., Fratino, P., Dalla Paola, L., Mariani, G., Mingardi, R., and Morabito, A. HYAFF 11-based autologous dermal and epidermal grafts in the treatment of noninfected diabetic plantar and dorsal foot ulcers: a prospective, multicenter, controlled, randomized clinical trial. Diabetes Care 26, 2853, 2003.

36. Huang, Z.M., Zhang, Y.Z., Kotaki, S., and Ramakrishna, S. A review on polymer nanofibers by electrospinning and their applications in nanocomposites. Composite Sci. Techol. 63, 2223, 2003.

37. Katti, D.A., Robinson, K.W., Ko, F.K., and Laurencin, C.T. Bioresorbable nanofiber-based systems for wound healing and drug delivery: optimization of fabrication parameters. J. Biomed. Mater. Res. B Appl. Biomater. 70B, 286, 2004.

38. Huang, L., Nagapudi, K., Apkarian, R.P., and Chaikof, E.L. Engineered collagen-PEO nanofibers and fabrics. J. Biomater. Sci. Polym. Ed. 12, 979, 2001.

39. Sipehia, R., Martucci, G., Barbarosie, M., and Wu, C. Enhanced attachment and growth of human endothelial cells derived from umbilical veins on ammonia plasma modified surfaces of PTFE and ePTFE synthetic vascular graft biomaterials. Biomat. Artif. Cells Immobil. Biotechnol. 21, 465, 1993.

40. Vohra, R.K., Thompson, G.J., Sharma, H., Carr, H.M., and Walker, M.G. Fibronectin coating of expanded polytetrafluoroethylene (ePTFE) grafts and its role in endothelial seeding. Artif. Org. 14, 41, 1990.

41. Schmidt, S.P., Hunter, T.J., Sharp, W.V., Malindzak, G.S., and Evancho, M.M. Endothelial cell-seeded four-millimeter Dacron vascular grafts: effects of blood flow manipulation through the grafts. J. Vasc. Surg. 1, 434, 1984.

42. Greisler, H.P., Kim, D.U., Price, J.B., and Voorhees, A.B. Arterial regenerative activity after prosthetic implantation. Arch. Surg. 120, 315, 1985.

43. Kim, B. and Mooney, D.J. Engineering smooth muscle tissue with a predefined structure. J. Biomed. Mater. Res. 41, 322, 1998.

44. Gao, J., Niklason, L., and Langer, R. Surface hydrolysis of poly(glycolic acid) meshes increases the seeding density of vascular smooth muscle cells. J. Biomed. Mater. Res. 42, 417, 1998.

45. Shum-Tim, D., Stock, U., Hrkach, J., Shinoka, T., Lien, J., Moses, M.A., Stamp, A., Taylor, G., Moran, A.M., Landis, 
W., Langer, R., Vacanti, J.P., and Mayer, J.E. Tissue engineering of autologous aorta using a new biodegradable polymer. Ann. Thorac. Surg. 68, 2298, 1999.

46. Matsumura, G., Hibino, N., Ikada, Y., Kurosawa, H., and Shinoka, T. Successful application of tissue engineered vascular autografts: clinical experience. Biomaterials 24, 2303, 2003.

47. Xu, C.Y., Inai, R., Kotaki, M., and Ramakrishna, S. Aligned biodegradable nanofibrous structure: a potential for blood vessel engineering. Biomaterials 25, 877, 2004.

48. Stankus, J.J., Soletti, L., Fujimoto, K., Hong, Y., Vorp, D.A., and Wagner, W.R. Fabrication of cell microintegrated blood vessel constructs through electrohydrodynamic atomization. Biomaterials 28, 2738, 2007.

49. Zund, G., Hoerstrup, S.P., Schoeberlein, A., Lachat, M., Ulcschmid, G., Vogt, P.R., and Turina, M. Tissue engineering: A new approach in cardiovascular surgery; seeding of human fibroblasts followed by endothelial cells on resorbable mesh. Eur. J. Cardiothorac. Surg. 13, 160, 1998.

50. Zund, G., Breuer, C.K., Shinoka, T., Ma, P.X., Langer, R., Mayer, J.E., and Vacanti, J.P. The in vivo construction of a tissue engineered bioprosthetic heart valve. Eur. J. Cardiothorac. Surg. 11, 493, 1997.

51. Hoerstrup, S.P., Kadner, A., Melnitchouk, S., Trojan, A., Eid, K., Tracy, J., Sodian, R., Visjager, J.F., Kolb, S.A., Grunenfelder, J., Zund, G., and Turina, M. Tissue engineering of functional trileaflet heart valves from human marrow stromal cells. Circulation 106, 1143, 2002.

52. Engelmayr, G.C., Hildebrand, D.K., Sutherland, F.W.H., Mayer, J.E., and Sacks, M.S. A novel bioreactor for the dynamic flexural stimulation of tissue engineered heart valve biomaterials. Biomaterials 24, 2523, 2003.

53. Nuutinen, J.P., Clerc, C., Reinikainen, R., and Tormala, P. Mechanical properties and in vitro degradation of bioabsorbable self-expanding braided stents. J. Biomater. Sci.: Polym. Ed. 14, 255, 2003.

54. Nguyen, K.T., Su, S.H., Sheng, A., Wawro, D., Schwade, N.D., Brouse, C.F., Greilich, P.E., Tang, L., and Eberhart, R.C. In vitro hemocompatability studies of drug-loaded poly-(L-lactic acid) fibers. Biomaterials 24, 5191, 2003.

55. Nuutinen, J.P., Valimaa, T., Clerc, C., and Tormala, P. Mechanical properties and in vitro degradation of bioresorbable knitted stents. J. Biomater. Sci. Polym. Ed. 13, 1313, 2002.

56. Saito, Y., Minami, K., Kobayashi, M., Nakao, Y., Omiya, H., Imamura, H., Sakaida, N., and Okamura, A. New tubular bioabsorbable knitted airway stent: biocompatibility and mechanical strength. J. Thorac. Cardiovasc. Surg. 123, 161, 2002.

57. Pereira Lopes, F.R., Camargo de Moura Campos, L., Dias Correa Jr., J., Balduino, A., Lora, S., Langone, F., Borojevic, R., and Blanco Martinez, A.M. Bone marrow stromal cells and resorbable collagen guidance tubes enhance sciatic nerve regeneration in mice. Exp. Neurol. 198, 457, 2006.

58. Pfister, L.A., Papaloizos, M., Merkle, H.P., and Gander, B. Hydrogel nerve conduits produced from alginate/chitosan complexes. J. Biomed. Mater. Res. A 80, 932, 2007.

59. Widmer, M.S., Gupta, P.K., Lu, L., Meszlenyi, R.K., Evans, G.R.D., Brandt, K., Savel, T., Gurlek, A., W., P.C., and Mikos, A.G. Manufacture of porous biodegradable polymer conduits by an extrusion process for guided tissue regeneration. Biomaterials 19, 1945, 1998.

60. Wang, S., Wana, C.A., Xua, X., Gaoa, S., Maob, H., Leong, K.W., and Yua, H. A new nerve guide conduit material composed of a biodegradable poly(phosphoester). Biomaterials 22, 1157, 2001.

61. Bini, T.B., Gao, S., Xu, X., Wang, S., Ramakrishna, S., and Leong, W. Peripheral nerve regeneration by microbraided poly(L-lactide-co-glycolide) biodegradable polymer fibers. J. Biomed. Mater. Res. A 68, 286, 2004.

62. Bini, T.B., Gao, S., Xu, X., Wang, S., and Ramakrishna, S. Development of fibrous biodegradable polymer conduits for guided nerve regeneration. J. Mater. Sci. Mater. Med. 16, 367, 2005.

63. Bini, T.B., Gao, S., Tan, T.C., Wang, S., Lim, A., Hai, L.M., and Ramakrishna, S. Electrospun poly(L-lactide-coglycolide) biodegradable polymer nanofibre tubes for pheripheral nerve regeneration. Nanotechnology 15, 1459, 2004.

64. Yoshii, S. and Oka, M. Peripheral nerve regeneration along collagen filament. Brain Res. 2001, 158, 2001.

65. Rangappa, N., Romero, A., D., N.K., Eberhart, R.C., and Smith, G.M. Laminin-coated poly(L-lactide) filaments induce robust neurite growth while proving directional orientation. J. Biomed. Mater. Res. 15, 625, 2000.

66. Steuer, H., Fadale, R., Muller, E., Muller, H.W., Planck, H., and Schlosshauer, B. Biohybrid nerve guide for regeneration: degradable polylactide fibers coated with rat Schwann cells. Neurosci. Lett. 277, 165, 1999.

67. Cheng, B. and Chen, Z. Fabrication autologous tissue to engineering artificial nerve. 22, 133, 2002.

68. Friedman, M.J., Berasi, C.C., and Fox, J.M. Preliminary results with abrasion arthroplasty in the osteoarthritic knee. Clin. Orthop. 4, 200, 1984.

69. Dzioba, R.B. The classification and treatment of acute articular cartilage lesions. Arthroscopy 4, 72, 1988.

70. Blevins, F.T., Steadman, J.R., and Rodrigo, J.J. Treatment of articular cartilage defects in athletes: an analysis of functional outcome and lesion appearance. Orthopedics 21, 761, 1998.

71. Bobic, V., Autologous osteo-chondral grafts in the management of articular cartilage lesions. Orthopedics 28, 19, 1999.

72. Vacanti, C.A., Langer, R., Schloo, B., and Vacanti, J.P. Synthetic polymers seeded with chondrocytes provide a template for new cartilage formation. Plast. Reconstr. Surg. 88, 753, 1991.

73. Zwingmann, J., Mehlhorn, A.T., Suüdkamp, N., Stark, B., Dauner, M., and Schmal, H. Chondrogenic differentiation of human articular chondrocytes differs in biodegradable PGA/PLA scaffolds. Tissue Eng. 13, 2335, 2007.

74. Banu, N., Banu, Y., Sakai, M., Mashino, T., and Tsuchiya, T. Biodegradable polymers in chondrogenesis of human articular chondrocytes. I Artif Organs 8, 184, 2005.

75. Solchaga, L.A., Temenoff, J.S., Gao, J., Mikos, A.G., and Caplan, A.L. Repair of osteochondral defects with hyaluronan- and polyester-based scaffolds. Osteoarthritis Cartilage 13, 297, 2005.

76. Cortivo, R., De Galateo, A., Castellani, I., and Abatangelo, G. Hyaluronic acid promotes chick embryo fibroblast and chondroblast expression. Cell. Biol. Int. Rep. 14, 111, 1990.

77. Brun, P., Abatangelo, G., Radice, M., Zacchi, V., Guidolin, D., Gordini, D.D., and Cortivo, R. Chondrocyte aggregation and reorganization into three-dimensional scaffolds. J. Biomed. Mater. Res. 46, 337, 1999.

78. Radice, M., Brun, R., Cortivo, R., Scapinelli, R., Battaliard, C., and Abatangelo, G. Hyaluronan-based biopolymers as delivery vehicles for bone-marrow-derived mesenchymal progenitors. J. Biomed. Mater. Res. 50, 101, 2000. 
79. Grigolo, B., Lisignoli, G., Piacentini, A., Fiorini, M., Gobbi, P., Mazzotti, G., Duca, M., Pavesio, A., and Facchini, A. Evidence for redifferentiation of human chondrocytes grown on a hyaluronan-based biomaterial (HYAFF 11): molecular, immunohistochemical and ultrastructural analyis. Biomaterials 23, 1187, 2002.

80. Lisignolim, G., Cristino, S., Piacentini, A., Toneguzzi, S., Grassi, F., Cavallo, C., Zini, N., Solimando, L., Maraldi, N.D., and Facchini, A. Cellular and molecular events during chondrogenesis of human mesenchymal stromal cells grown in a three-dimensional hyaluronan based scaffold. Biomaterials 26, 5677, 2005.

81. Aigner, J., Tegeler, J., Hutzler, P., Campoccia, D., Pavesio, A., Hammer, C., Kastenbauer, E., and Naumann, A. Cartilage tissue engineering with novel nonwoven structures biomaterial based on hyaluronic acid benzyl ester. J. Biomed. Mater. Res. 42, 172, 1998.

82. Blunk, T., Sieminski, A.L., Gooch, K.J., Courter, D.L., Hollander, A.P., Nahir, A.M., Langer, R., Vunjak-Novakovic, G., and Freed, L.E. Differential effects of growth factors on tissue engineered cartilage. Tissue Eng. 8, 73, 2002.

83. Freed, L.E., Langer, R., Martin, I., Pellis, N., and VunjakNovakovic, G. Tissue engineering of cartilage in space. Proc. Natl. Acad. Sci. U S A 94, 13885, 1997.

84. Vunjak-Novakovic, G., Martin, I., Obradovic, B., Treppo, T., Grodzinsky, A.J., and Freed, L.E. Bioreactor cultivation conditions modulate the composition and mechanical properties of tissue-engineered cartilage. J. Orthop. Res. 17, 130, 1999.

85. Obradovic, B., Martin, I., Padera, R., Treppo, S., Freed, L., and Vunjak-Novakovic, G. Integration of engineered cartilage. J. Orthop. Res. 19, 1089, 2001.

86. Ma, P.X., Schloo, B., Mooney, D., and Langer, R. Development of biomechanical properties and morphogenesis of in vitro tissue engineered cartilage. J. Biomed. Mater. Res. 29, 1587, 1995.

87. Ameer, G.A., Mahmood, T.A., and Langer, R.A. A biodegradable composite scaffold for cell transplantation. J. Orthop. Res. 20, 16, 2002.

88. Cohen, S.B., Meirisch, C.M., Wilson, H.A., and Diduch, D.R. The use of absorbable co-polymer pads with alginate and cells for articular cartilage repair in rabbits. Biomaterials 24, 2653, 2003.

89. Ushida, T., Furukawa, K., Toita, K., and Tateishi, T. Threedimensional seeding pf chondrocytes encapsulated in collagen gel into PLLA scaffolds. Cell Transplantation 11, 489, 2002.

90. Chen, G., Sato, T., Ushida, T., Hirochika, R., Shirasaki, Y., Ochiai, N., and Tateishi, T. The use of a novel PLGA fiber/collagen composite web as a scaffold for engineering of articular cartilage with adjustable thickness. J. Biomed. Mater. Res. A 67, 1170, 2003.

91. Davisson, T., Sah, R.L., and Ratcliffe, A. Perfusion increases cell content and matrix sythesis in chondrocyte threedimensional culture. Tissue Eng. 8, 807, 2002.

92. Griffon, D.J., Sedighi, M.R., Urkmez, A.S., Stewart, A.A., and Jaminson, R. Evaluation of vacuum and dynamic cell seeding of polyglycolic acid and chitosan scaffolds for cartilage engineering. Am. J. Vet. Res. 66, 599, 2005.

93. Li, W.J., Danielson, K.G., Alexander, P.G., and Tuan, R.S. Biological response of chondrocytes cultured in threedimensional nanofibrous poly(e-caprolactone) scaffolds. J. Biomed. Mater. Res. 67A, 1105, 2003.
94. Li, W.J., Tuli, R., Okafar, C., Derfoul, A., Danielson, K.G., Hall, D.J., and Tuan, R.S. A three-dimensional nanofibrous scaffold for cartilage tissue engineering using mesenchymal stem cells. Biomaterials 26, 599, 2005.

95. Matthews, J.A., Boland, E.D., Wnek, G.E., Simpson, D.G., and Bowlin, G.L. Electrospinning of collagen type II: a feasibility study. J. Bioact. Compat. Polym. 18, 125, 2003.

96. Sikavitsas, V., Bancroft, G.N., Lemoine, J.J., Liebscner, M.A.K., Dauner, M., and Mikos, A.G. Flow perfusion enhances the calcified matrix deposition of marrow stromal cells in biodegradable nonwoven fiber mesh scaffolds. Ann. Biomed. Eng. 33, 63, 2005.

97. Salgado, A.J., Coutinho, O.P., Reis, R.L., and Davies, J.E. In vivo response to starch-based scaffolds designed for bone tissue engineering applications. J. Biomed. Mater. Res. A 80, 983, 2007.

98. Morgan, S.M., Tilley, S., Perera, S., Ellis, M.J., Kanczler, J., Chaudhuri, J.B., Oreffo, R.O.C. Expansion of human bone marrow stromal cells on poly-(dl-lactide-co-glycolide) (PDLLGA) hollow fibres designed for use in skeletal tissue engineering. Biomaterials 28, 5332, 2007.

99. Jiang, T., Abdel-Fattah, W.I., and Laurencin, C.T. In vitro evaluation of chitosan/poly(lactic acid-glycolic acid) sintered microsphere scaffolds for bone tissue engineering. Biomaterials 27, 4894, 2006.

100. Tuzlakoglu, K. and Reis, R.L. Formation of bone-like apatite layer on chitosan fiber mesh scaffolds by a biomimetic spraying process. J. Mater. Sci. Mater. Med. 18, 1279, 2007.

101. Liu, X. and Ma, P.X. Polymeric scaffolds for bone tissue engineering. Ann. Biomed. Eng. 32, 477, 2004.

102. Hutmacher, D.W. Scaffold design and fabrication technologies for engineering tissues-state of the art and future perspectives. J. Biomater. Sci. Polym. Ed. 12, 107, 2001.

103. Lisignolim, G., Zini, N., Remiddi, G., Piacentini, A., Puggioli, A., Trimarchi, C., Fini, M., Maraldi, N.D., and Facchini, A. Basic fibroblast growth factor enhances in vitro mineralization of rat bone marrow stromal cells grown on non-woven hyaluronic acid based polymer scaffold. Biomaterials 22, 2095, 2001.

104. Lisignolim, G., Fini, M., Giavaresi, G., Aldini, N., Toneguzzi, S., and Facchini, A. Osteogenesis of large segmental radius defects enhanced by basic fibroblast growth factor activated bone marrow stromal cells grown on non-woven hyaluronic acid-based polymer scaffold. Biomaterials 23, 1043, 2002.

105. Gomes, M.E., Sikavitas, V.I., Behravesh, E., Reis, R.L., and Mikos, A.G. Effect of flow perfusion on the osteogenic differantiation of bone marrow stromal cells cultured on starch-based three-dimensional scaffolds. J. Biomed. Mater. Res. A, 67A, 87, 2003.

106. Tuzlakoglu, K., Alves, C.M., Mano, J.F., and Reis, R.L. Production and characterization of chitosan fibers and 3-D fiber mesh scaffolds for tissue engineering applications. Macromol. Biosci. 4, 811, 2004.

107. Eichhorn, S.J. and Sampson, W.W. Statistical geometry of pores and statistics of porous nanofibrous assemblies. J. R. Soc. Interface 2, 309, 2005.

108. Li, W.J., Tuli, R., Huan, X., Laquerriere, P., and Tuan, R.S. Multilineage differentiation of human mesenchymal stem cell in a three-dimensional nanofibrous scaffold. Biomaterials 26, 5158, 2005.

109. Jin, H.J., Chen, J., Karageorgiou, V., Altman, G.H., and Kaplan, D.L. Human bone marrow stromal cell responses 
on electrospun silk fibroin mats. Biomaterials 25, 1039, 2004.

110. Tuzlakoglu, K., Bolgen, N., Salgado, A.J., Gomes, M.E., Piskin, E., and Reis, R.L. Nano- and micro-fiber combined scaffolds: A new architecture for bone tissue engineering. J. Mater. Sci. Mater. Med. 16, 1099, 2005.

111. Taddei, P., Monti, P., and Simoni, R. Vibrational and thermal study on the in vitro and in vivo degradation of a bioresorbable periodontal membrane: Vicryl periodontal (polyglactin 90). J. Mater. Sci. Mater. Med. 13, 59, 2002.

112. Soncini, M., Rodriguez, R., Baena, R., Pietrabissa, R., Quaglini, V., Rizzo, S., and Zaffe, D. Experimental procedure for the evaluation of the mechanical properties of the surrounding dental implants. Biomaterials 23, 9, 2002.

113. Park, Y.J., Nam, K.H., Ha, S.J., Pai, C.M., Chung, C.P., and Lee, S.J. Porous poly(L-lactide) membranes for guided tissue regeneration and controlled drug delivery: membrane fabrication and characterization. J. Control Rel. 43, 151, 1997.

114. Fujihara, K., Kotaki, M., and Ramakrishna, S. Guided bone regeneration membrane made of polycaprolactone/calcium carbonate composite nano-fibers. Biomaterials 26, 4139, 2005.

115. Chvapil, M., Speer, D.P., Holubec, H., Chvapil, T.A., and King, D.H. Collagen fibers as a temporary scaffold for replacement of ACL in goats. J. Biomed. Mater. Res. 27, 313, 1993.

116. Caruso, A.B. and Dunn, M.G. Changes in mechanical properties and cellularity during long-term culture of collagen fiber ACL reconstruction scaffolds. J. Biomed. Mater. Res., 388, 2005.

117. Altman, G.H., Horan, R.L., Lu, H.H., Moreau, J., Martin, I., Richmond, J.C., and Kaplan, D.L. Silk matrix for tissue engineered anterior cruciate ligaments. Biomaterials 23, 4131, 2002.

118. Cristino, S., Grassi, F., Toneguzzi, S., Piacentini, A., Grigolo, B., Santi, S., Riccio, M., Tognana, E., Facchini, A., and Lisignoli, G. Analysis of mesenchymal stem dimensional HYAFF 11 (R)-based cells grown on a prototype ligament scaffold. J. Biomed. Mater. Res. 73A, 275, 2005.
119. Puddu, G., Cipolla, M., Cerullo, G., Franco, V., Giannì, E. Anterior cruciate ligament reconstruction and augmentation with PDS graft. Clin. Sports Med. 12, 13, 1993.

120. Buma, P., Kok, H.J., Blankevoort, L., Kuijpers, W., Huiskes, R., and Kampne, A. Augmentation in anterior cruciate ligament reconstruction-a histological and biomedical study on goats. Int. Orthoped. 28, 91, 2004.

121. Cabaud, H.E., Feagin, J.A., and Rodkey, W.G. Acute anterior cruciate ligament injury and repair reinforced with a biodegradable intraarticular ligament: experimental studies. Am. J. Sports Med. 10, 259, 1982.

122. Laitinen, O., Tormala, P., Ritva, T., Kai, S., Saarelainen, K., Livonen, T., and Vainionpaa, S. Mechanical properties of biodegradable ligament augmentation device of poly(L-lactide) in vitro and in vivo. Biomaterials 13, 1012, 1992.

123. Lu, H.H., Cooper, J.A., Manuel, S., Freeman, J.W., Attawia, M.A., and Ko, F.K., Laurencin, C. T. Anterior cruciate ligament regeneration using braided biodegradable scaffolds: in vitro optimization studies. Biomaterials 26, 4805, 2005.

124. Cooper, J.A., Lu, H.H., Ko, F.K., Freeman, J.W., and Laurencin, C.T. Fiber-based tissue-engineered scaffold for ligament replacement: design considerations and in vitro evaluation. Biomaterials 26, 1523, 2005.

Address reprint requests to: Kadriye Tuzlakoglu, Ph.D.

Biomaterials, Biodegradables and Biomimetics Research Group Department of Polymer Engineering University of Minho Campus de Gualtar

Braga Portugal

E-mail: kadriye@Departmentuminho.pt

Received: January 10, 2008

Accepted: September 26, 2008

Online Publication Date: December 17, 2008 



\section{This article has been cited by:}

1. Sangwon Chung, Mike P Gamcsik, Martin W King. 2011. Novel scaffold design with multi-grooved PLA fibers. Biomedical Materials 6:4, 045001. [CrossRef]

2. Christoph Brenner, Wolfgang-M Franz. 2011. The use of stem cells for the repair of cardiac tissue in ischemic heart disease. Expert Review of Medical Devices 8:2, 209-225. [CrossRef]

3. Frederick J Schoen. 2011. Heart valve tissue engineering: quo vadis?. Current Opinion in Biotechnology . [CrossRef]

4. Byung-Soo Kim, In-Kyu Park, Takashi Hoshiba, Hu-Lin Jiang, Yun-Jaie Choi, Toshihiro Akaike, Chong-Su Cho. 2011. Design of artificial extracellular matrices for tissue engineering. Progress in Polymer Science 36:2, 238-268. [CrossRef]

5. Alisa Morss Clyne. 2011. Thermal Processing of Tissue Engineering Scaffolds. Journal of Heat Transfer 133:3, 034001. [CrossRef]

6. Paula M. López-Pérez, Ricardo M.P. da Silva, Rui A. Sousa, Iva Pashkuleva, Rui L. Reis. 2010. Plasma-induced polymerization as a tool for surface functionalization of polymer scaffolds for bone tissue engineering: An in vitro study. Acta Biomaterialia 6:9, 3704-3712. [CrossRef]

7. Serghei Cebotari, Igor Tudorache, Tobias Schilling, Axel Haverich. 2010. Tissue Engineering von Herzklappen und Myokard. Herz 35:5, 334-341. [CrossRef]

8. Fa-Ming Chen, Min Zhang, Zhi-Fen Wu. 2010. Toward delivery of multiple growth factors in tissue engineering. Biomaterials 31:24, 6279-6308. [CrossRef]

9. Scott A. Zawko, Christine E. Schmidt. 2010. Crystal templating dendritic pore networks and fibrillar microstructure into hydrogels. Acta Biomaterialia 6:7, 2415-2421. [CrossRef]

10. Marta Codina, Jeremy Elser, Kenneth B. Margulies. 2010. Current Status of Stem Cell Therapy in Heart Failure. Current Cardiology Reports 12:3, 199-208. [CrossRef]

11. Fa-Ming Chen, Yan Jin . 2010. Periodontal Tissue Engineering and Regeneration: Current Approaches and Expanding OpportunitiesPeriodontal Tissue Engineering and Regeneration: Current Approaches and Expanding Opportunities. Tissue Engineering Part B: Reviews 16:2, 219-255. [Abstract] [Full Text] [PDF] [PDF Plus]

12. Lance C. Visser, Steven P. Arnoczky, Oscar Caballero, Andreas Kern , Anthony Ratcliffe , Keri L. Gardner . 2010. Growth Factor-Rich Plasma Increases Tendon Cell Proliferation and Matrix Synthesis on a Synthetic Scaffold: An In Vitro StudyGrowth Factor-Rich Plasma Increases Tendon Cell Proliferation and Matrix Synthesis on a Synthetic Scaffold: An In Vitro Study. Tissue Engineering Part A 16:3, 1021-1029. [Abstract] [Full Text] [PDF] [PDF Plus]

13. Seth D. McCullen, Carla M. Haslauer, Elizabeth G. Loboa. 2010. Fiber-reinforced scaffolds for tissue engineering and regenerative medicine: use of traditional textile substrates to nanofibrous arrays. Journal of Materials Chemistry 20:40, 8776. [CrossRef]

14. Isabel B. Leonor, Márcia T. Rodrigues, Manuela E. Gomes, Rui L. Reis. 2010. In situ functionalization of wet-spun fibre meshes for bone tissue engineering. Journal of Tissue Engineering and Regenerative Medicine n/a-n/a. [CrossRef]

15. Fang Yang, Sanne K. Both, Xuechao Yang, X. Frank Walboomers, John A. Jansen. 2009. Development of an electrospun nano-apatite/PCL composite membrane for GTR/GBR application. Acta Biomaterialia 5:9, 3295-3304. [CrossRef] 